\title{
Hip fracture rates and bisphosphonate consumption in Spain. An ecologic study
}

\author{
L. H. Martín Arias • C. Treceño • P. García-Ortega • \\ J. Rodríguez-Paredes • A. Escudero • M. Sáinz • \\ I. Salado $\cdot$ V. Velasco $\cdot$ A. Carvajal
}

Received: 18 April 2012 / Accepted: 12 June 2012

(C) Springer-Verlag 2012

\begin{abstract}
Introduction Bisphosphonates are used worldwide to treat osteoporosis and, thus, to prevent fractures. Though they have been proven in clinical trials to avoid some fractures, their effectiveness in reducing hip fractures is unclear. The aim of the present study was to explore the relationship between bisphosphonate use and hip fracture trends in Spain.

Methods For this purpose, an ecologic study spanning 2002 to 2008 was conducted in Spain. Consumption data were obtained from the Spanish Ministry of Health and Social Policy. The number of hip fractures was obtained from hospital discharges; annual hip fracture rates were determined and standardized using the Spanish 2002 population census. A linear regression was performed between fracture rate and use of bisphosphonates; $R^{2}$ and Pearson correlation coefficient were calculated.

Results From 2002 to 2008, dispensed prescriptions of bisphosphonates in Spain increased from 3.28 to 17.66 $\mathrm{DDD} / 1,000$ inhabitants per day. In the same period, the crude hip fracture rate increased from 2.85 to 3.02 cases per 1,000 inhabitants older than 50 years; however, when age standardized rates were estimated, the rate declined from 2.85 to 2.79 . Analyzed by sex, the standardized rate for men slightly increased from 1.45 to 1.48 , while for women the rate significantly dropped from 4.00 to 3.91 .
\end{abstract}

L. H. M. Arias $\cdot$ C. Treceño $\cdot$ P. García-Ortega $\cdot$

J. Rodríguez-Paredes $\cdot$ A. Escudero $\cdot$ M. Sáinz $\cdot$ I. Salado •

V. Velasco $\cdot$ A. Carvajal

Centro de Estudios sobre la Seguridad de los Medicamentos,

Universidad de Valladolid,

Valladolid, Spain

\author{
A. Carvajal $(\bowtie)$ \\ Facultad de Medicina, \\ Ramón y Cajal 7, \\ 47005 Valladolid, Spain \\ e-mail: carvajal@ife.uva.es
}

Conclusion A small effect of bisphosphonates on hip fracture rates can not be ruled out; however, other factors might partially explain this decline. Assuming this medication was the only cause for hip fracture rate reduction, the elevated medication cost to avoid a single hip fracture makes it necessary to explore less expensive interventions.

Keywords Hip fracture $\cdot$ Bisphosphonate $\cdot$ Osteoporosis

\section{Introduction}

Hip fractures are common in the elderly and are associated with a high morbidity and mortality [1]; older adults have a five- to eightfold increased risk for all-cause mortality during the first 3 months after hip fracture [2]. A review of the outcomes after hip fracture over a 40-year period (19591998) showed that, in this period, mortality remained essentially unchanged at 6 and 12 months after the fracture [3].

The population over 50 years of age has significantly increased worldwide in recent years. In Spain, it increased by $18.9 \%$ over the period 2000-2009 [4]; the population older than 85 years increased by $42.4 \%$ in the same period. The elderly population is more vulnerable to certain diseases; for instance, it has been estimated that almost 4 million people in Spain might currently suffer from osteoporosis [5]. Osteoporosis in turn is associated with a high risk of fractures - the most troublesome being hip fractures - and disability, and with substantial medical costs. In an attempt to reduce this enormous disease burden, osteoporosis is widely treated in order to prevent fractures; bisphosphonates are the medications most used for this goal [6]. However, in spite of their widespread use, their effectiveness in reducing hip fractures in the general population is a matter of controversy [7]. Moreover, long-term treatment with bisphosphonates has recently been associated with an increased risk of subtrochanteric or 
femoral shaft fractures, although the absolute risk of these atypical fractures associated with bisphosphonate use seems to be very low [8]. Therefore, the aim of the present study was to explore the relationship between bisphosphonate use and hip fracture trends in Spain.

\section{Methods}

For the purpose, an ecologic comparison study spanning 2002 to 2008 was conducted [9]. During that period, we observed the evolution of both bisphosphonate consumption and hip fracture rates in Spain. Consumption and economic data were obtained from the DGPS (Dirección General de Farmacia y Productos Sanitarios) database of the Spanish Ministry of Health and Social Policy [10]. This database offers information on the consumption and cost of the medications dispensed by pharmacies at the expense of the Spanish National Health System, which covers almost the whole population; it does not include hospital consumption, consumption paid by the patient or private insurers, or the consumption of non-prescription drugs or drugs not covered by the National Health System. This database was conceived for administrative purposes: it serves to control and follow payments to pharmacists, following a specific process for registering prescriptions. In no way is this information collected as in a clinical history, and the database does not include information about age, sex or specialty of prescribing physicians. The risk of duplicate or missing information is almost null.

Data were expressed in defined daily doses (DDD) per 1,000 inhabitants per day (DDD/1,000), using the DDD values proposed by the WHO $[11,12]$. The following formula was used: number of DDD per 1,000 inhabitants per day $=($ number of packages dispensed $\times$ number of doses per package $\times$ number of $\mathrm{mg}$ per dose $\times 1,000$ inhabitants)/ (DDD in $\mathrm{mg} \times$ number of inhabitants in the geographic area for the year $\times 365$ days).

Annual hip fracture rates by age and sex were calculated and then we performed a direct standardization using the Spanish 2002 population age distribution as a reference [4]; we used 5-year groups to perform standardization as this provides estimates that can be compared directly from one year to another without the confounding effects of changes in age distribution over time. Numbers of hip fractures were obtained from the CMBD-H (Minimum Dataset-Hospitalization), which is publicly available at the Spanish Ministry of Health and Social Policy website [13]; the ICD-9-MC diagnosis code 820 was used. Annual medication costs are periodically published by this Ministry [14].

The relationship between hip fracture incidence rate and bisphosphonate use was examined by calculating
Pearson's correlation and by linear regression analysis. Statistical analysis was performed using the summary.im $\mathrm{R}$ function [15].

\section{Results}

Spain had 45,593,385 inhabitants as of July 1 st 2008 . Over the period 2002-2008, the population older than 50 years increased by $12.4 \%$ (women, $11.8 \%$; men, $13.0 \%$ ) and those older than 80 years, by $28.8 \%$. In the year 2008 , this oldest group represented $4.6 \%$ of the whole population.

From 2002 to 2008 , dispensed prescriptions of bisphosphonates in Spain increased from 3.28 to 17.66 DDD/1,000 inhabitants per day. Meanwhile, the number of hip fractures increased from 39,920 to 47,308 . In the same period, the crude hip fracture rate increased from 2.85 to 3.02 cases per 1,000 inhabitants older than 50 years. However, when age standardized rates were estimated, the rate declined from 2.85 to 2.79 per 1,000 inhabitants older than 50 years (Fig. 1). When analyzed by sex, the standardized rate slightly increased in men, from 1.45 to 1.48 cases per 1,000 inhabitants older than 50 years (Fig. 2a), while it significantly dropped in women, from 4.00 to 3.91 cases per 1,000 inhabitants older than 50 years (Fig. 2b).

Age and gender structure of the population has changed over the last years in Spain. Table 1 shows this structure linked with the incidence rates of hip fractures.

\section{Discussion}

Despite the initial findings from the crude analysis, standardization showed that, although weak, there was a statistically significant correlation between increase in bisphosphonate consumption and decline in hip fracture rates; this was observed only in women. Whether this decline was due to bisphosphonate use might be a matter of debate. The fact that a decline did occur in women points to a causal relationship, since women are the main users of this medication. At the same time, as they show a higher risk of hip fractures than men, they are more prone to be the target of specific health advice or campaigns intended to curb the number of hip fractures in the population; furthermore, in the near 10-year period of the study, individuals at a higher risk, when becoming aware of such a risk, may have subtly modified their behavior and environment.

A relevant question to be posed is that of the relationship between benefits and costs. Assuming a beneficial effect of bisphosphonates in hip fracture prevention and based on our current data, we would need 83,082 DDD to avoid one single hip fracture a year or, similarly, to continuously treat 
Fig. 1 Relationship between the total annual number of prescriptions (DDD/1,000 inhabitants per day) for bisphosphonate use and standardized hip fracture rates (per 1,000 persons) in the total Spanish population older than 50 years $(2002-2008)$ $\left(p=0.043 * ; R^{2}=0.59\right)$

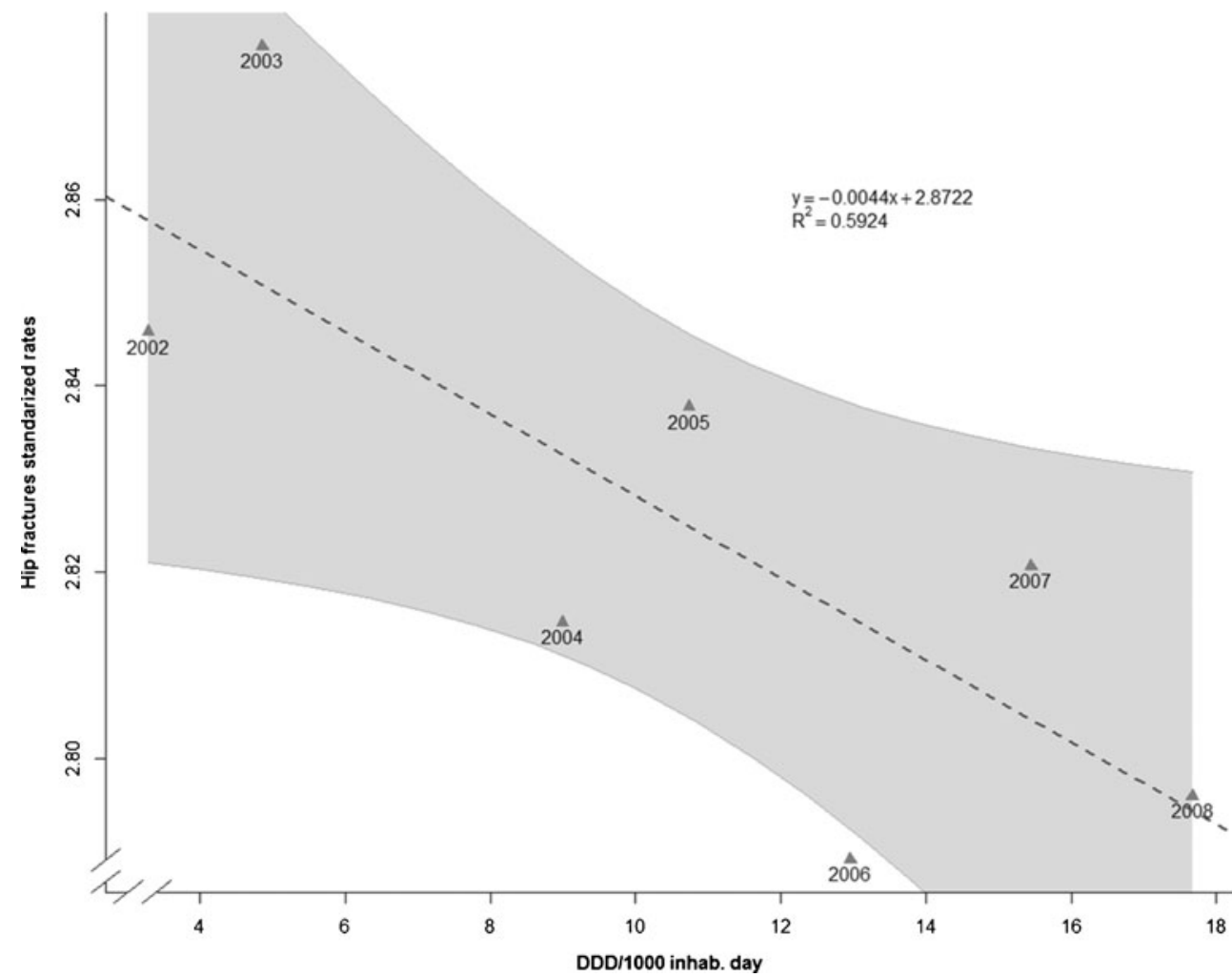

228 persons a year (Fig. 1b). Considering that the average cost for these drugs was $€ 0.919$ per day in 2008 [10], the total cost to avoid a hip fracture would be $€ 76,352$. The direct health care costs of hip fractures, as calculated by the Spanish National Health Service,

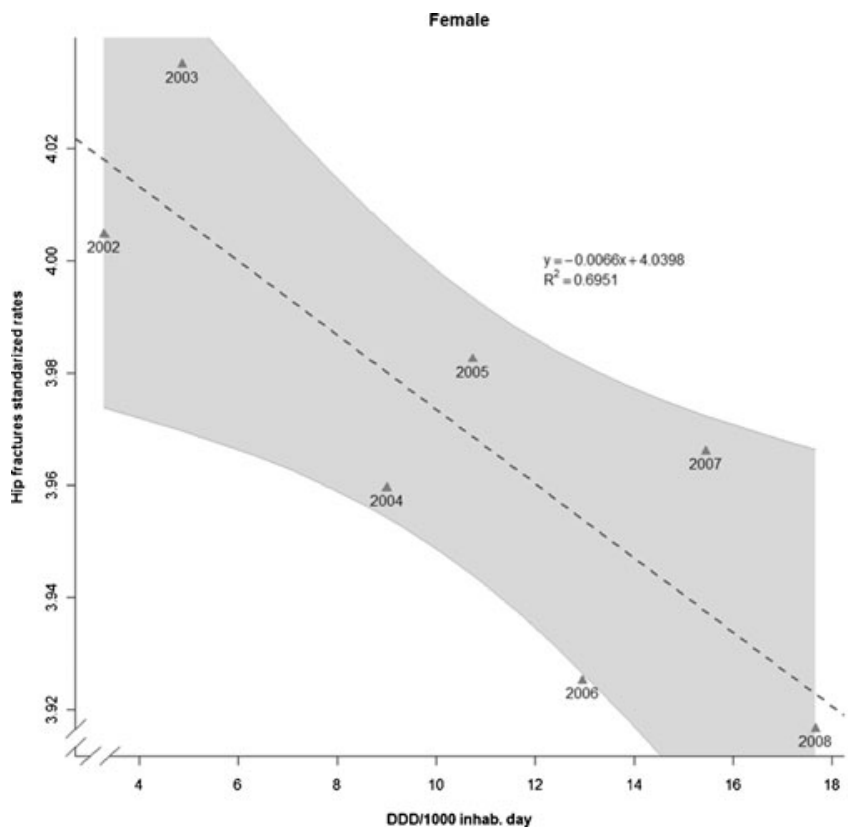

Fig. 2 Relationship between the total annual number of prescriptions (DDD/1,000 inhabitants per day) for bisphosphonate use and age-standardized hip fracture rates (per 1,000 persons) in reached $€ 7,713$ per hip fracture [13]; indirect costs of hip fractures, cost per day deflation because of the growing consumption of generic medications as well as the cost relative to bisphosphonates' adverse effects should be also taken into account.

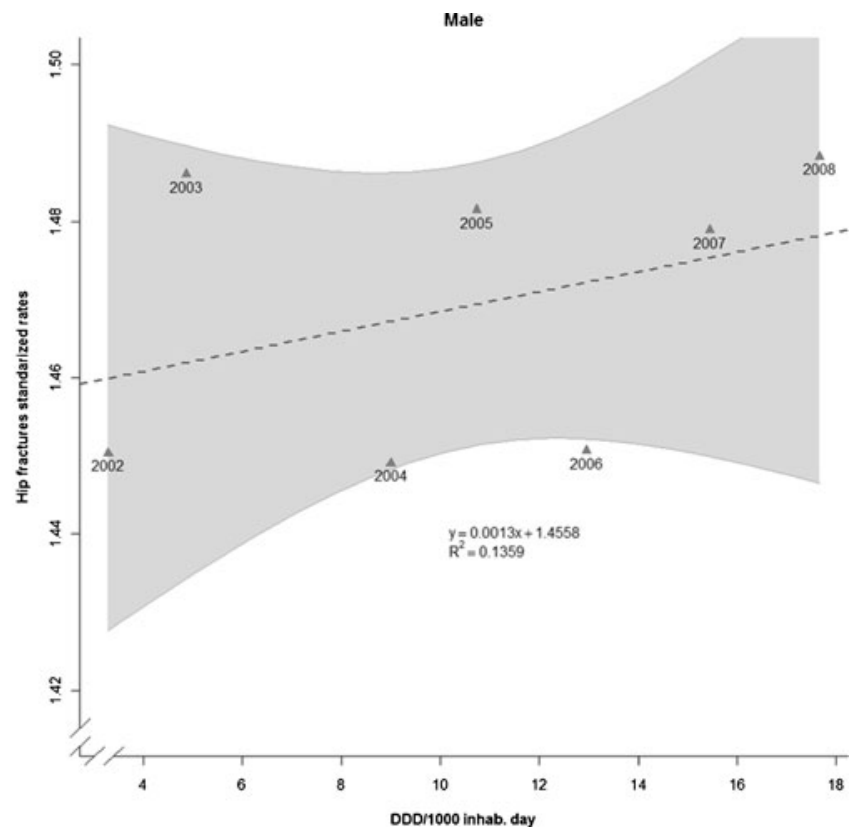

the total Spanish population older than 50 years $(2002-2008)$ for a women $\left(p=0.0198^{*} ; R^{2}=0.70\right)$ and for $\mathbf{b}$ men $(p=0.416$; $\left.R^{2}=0.14\right)$ 
Eur J Clin Pharmacol

Table 1 Incidence rates of hip fractures per 1,000 persons older than 50 years in the Spanish population

\begin{tabular}{lllllllll}
\hline & Age group (years) & 2002 & 2003 & 2004 & 2005 & 2006 & 2007 & 2008 \\
\hline Men & $50-54$ & 0.22 & 0.21 & 0.19 & 0.20 & 0.22 & 0.22 & 0.20 \\
& $55-59$ & 0.27 & 0.32 & 0.29 & 0.29 & 0.27 & 0.28 & 0.27 \\
& $60-64$ & 0.40 & 0.39 & 0.40 & 0.45 & 0.39 & 0.43 & 0.42 \\
& $65-69$ & 0.68 & 0.70 & 0.61 & 0.65 & 0.66 & 0.63 & 0.66 \\
& $70-74$ & 1.31 & 1.33 & 1.23 & 1.32 & 1.29 & 1.23 & 1.26 \\
& $75-79$ & 2.80 & 2.78 & 2.76 & 2.72 & 2.54 & 2.71 & 2.68 \\
& $80-84$ & 5.52 & 5.67 & 5.82 & 5.90 & 5.75 & 5.86 & 6.03 \\
& $85-89$ & 10.20 & 10.94 & 10.61 & 10.62 & 10.96 & 11.17 & 11.41 \\
& $90-94$ & 16.89 & 17.06 & 16.76 & 17.42 & 17.09 & 17.32 & 17.42 \\
& $95+$ & 21.67 & 22.16 & 22.39 & 21.85 & 22.70 & 24.21 & 22.17 \\
& All & 1.45 & 1.51 & 1.49 & 1.55 & 1.53 & 1.59 & 1.62 \\
& $50-54$ & 0.13 & 0.13 & 0.14 & 0.14 & 0.13 & 0.14 & 0.14 \\
& $55-59$ & 0.26 & 0.28 & 0.26 & 0.28 & 0.25 & 0.28 & 0.27 \\
& $60-64$ & 0.51 & 0.49 & 0.52 & 0.46 & 0.49 & 0.57 & 0.51 \\
& $65-69$ & 1.14 & 1.19 & 1.12 & 1.10 & 1.04 & 0.99 & 1.00 \\
$70-74$ & 2.79 & 2.81 & 2.65 & 2.56 & 2.51 & 2.61 & 2.44 \\
& $75-79$ & 6.35 & 6.43 & 6.40 & 6.25 & 6.04 & 6.10 & 5.98 \\
$80-84$ & 12.84 & 12.75 & 12.39 & 13.00 & 12.71 & 12.65 & 12.45 \\
$85-89$ & 21.08 & 21.45 & 21.18 & 21.35 & 21.44 & 21.76 & 21.69 \\
$90-94$ & 28.69 & 28.45 & 28.41 & 28.62 & 28.92 & 28.66 & 28.94 \\
& $95+$ & 30.52 & 30.31 & 30.84 & 30.23 & 31.68 & 33.26 \\
All & 4.00 & 4.08 & 4.06 & 4.14 & 4.13 & 4.22 & 4.20 \\
\hline
\end{tabular}

Hip fracture is associated with high morbidity and is widely regarded as a life-threatening event in the elderly. The prevention of osteoporosis-associated fractures should include fall prevention, calcium supplementation, and lifestyle advice as well as, when necessary, pharmacological therapy with agents with proven antifracture efficacy [16]. Although there is evidence of the antifracture efficacy, including for hip fractures, of bisphosphonates in clinical trials [17-21], observational studies examining effectiveness found opposite results $[22,23]$. In a community cohort of postmenopausal women at risk, the fracture risk of patients who received bisphosphonates did not differ significantly from those who did not [21]; the same has been recently observed in another large cohort of post-menopausal women in Spain [23]. Moreover, atypical fractures of the femoral shaft associated with long-term bisphosphonate use have been observed to occur [24-27].

Our results are rather close to those found in the abovementioned cohort studies but differed from those seen in another ecologic study carried out in Australia [28]. In this latter study, it was observed that a drop in the use of bisphosphonates was associated with an increase in hip fracture rates in women. The fact that the study referred to a small population might explain those differences; other explanations could be differences in medication adherence or in secular trends in hip fractures.
Prior trends of hip fractures are important for understanding the impact of bisphosphonate consumption. In the Spanish region of Cantabria hip fracture crude rates did increase between 1988 and 2002 [29]; however, following age adjustment, no significant changes were found during that period. In our study, we observed a similar increase in crude hip fracture rates but a mild decrease in the standardized hip fracture trend following increased use of bisphosphonates. In the United States, Switzerland, Denmark, and Canada standardized hip fracture rates, after a previous long term steady trend, are now declining; reasons seem to be more complicated than simply increased patterns of diagnosis and treatment for osteoporosis, and some factors such as changing smoking habits, obesity, improved general health conditions, vitamin D supplementation, and institution-dwelling should be considered [7, 30-32].

Our study has some limitations. First, there may be inaccurate reasoning since ecologic studies focus on the comparison of groups, rather than on individuals. Second, there may also be a temporal ambiguity: the time trend studied and bisphosphonate efficacy associated with hip fractures rates may have different latent periods. A third limitation is that ecologic studies do not provide information about different etiologic agents that contribute to hip fracture rates, such us proton pump inhibitors, psychotropic medications, corticosteroids, etc, and we were therefore 
unable to control for all of them. A fourth limitation is the method used to calculate drug consumption figures: DDD is an approximate unit of measurement and does not necessarily reflect the real daily dose consumed. A fifth limitation is the quality of the information; databases of the Spanish Ministry of Health and Social Policy do not include consumption in hospitals, so our results refer exclusively to the consumption in the primary care or non-hospital setting; also, the database we used does not include prescriptions written by insurance companies or private practitioners; however, the almost universal coverage of the Spanish National Health System and the almost certain hospitalization of people with hip fractures minimize this possible bias. The consumption data do not include the gender of the person who received the prescriptions; thus, we were unable to analyze the use of these medications separately by men and women. To explore the relationship with hip fracture rates in men and women we assumed a similar evolution of bisphosphonate consumption in both sexes. Finally, the CMBD is a database originally intended for administrative purposes; however, it has been validated and is currently and widely used for epidemiological studies [33]. At the same time, our overall estimate of 2.8 cases per 1,000 inhabitants older than 50 years in 2002 is very similar to that of Hernández in Cantabria (Spain) of 2.6 cases per 1,000 inhabitants [29]. The latter estimate was made through clinical records from emergency units and the orthopedic surgical units of all hospitals in Cantabria along with admission and discharge files from these hospitals

In summary, the substantial increase in bisphosphonate use in Spain from 2002 to 2008 weakly but significantly correlates with a drop $(2.2 \%)$ in standardized hip fracture rates in women during that period. An effect of this medication on hip fracture reduction can not be ruled out; nevertheless, other factors could partially explain this decline, i.e., lifestyle advice, particular health campaigns, selfawareness, improvement in residence conditions, calcium supplementation, dietetic changes, or institution-dwelling [30]. All in all, even assuming that bisphosphonates were the only cause for hip fracture rate reduction, the elevated medication cost to avoid a single hip fracture makes it necessary to explore less expensive interventions.

\section{References}

1. Cummings-Vaughn LA, Gammack JK (2011) Falls, osteoporosis, and hip fractures. Med Clin North Am 95:495-506

2. Haentjens P, Magaziner J, Colón-Emeric CS, Vanderschueren D, Milisen K, Velkeniers B, Boonen S (2010) Meta-analysis: excess mortality after hip fracture among older women and men. Ann Intern Med 152:380-390
3. Haleem S, Lutchman L, Mayahi R, Grice JE, Parker MJ (2008) Injury. Mortality following hip fracture: trends and geographical variations over the last 40 years. Injury 39:1157-1163

4. National Statistics Institute (2012) Population in Spain. http:// www.ine.es/

5. de Felipe R, Cáceres C, Cimas M, Dávila G, Fernández S, Ruiz T (2010) Clinical characteristics of patients under treatment for osteoporosis in a Primary Care Centre. Who do we treat? Aten Primaria 42:559-563

6. Duarte J, Bolge S, Sen S (2007) An evaluation of patients' preferences for osteoporosis medications and their attributes: the PREFER-International study. Clin Ther 29:488-503

7. Melton LJ 3rd, Kanis JA, Johnell O (2005) Potential impact of osteoporosis treatment on hip fracture trends. J Bone Miner Res 20:895-897

8. Shane E, Burr D, Ebeling PR, Abrahamsen B, Adler RA, Brown TD, Cheung AM, Cosman F, Curtis JR, Dell R, Dempster D, Einhorn TA, Genant HK, Geusens P, Klaushofer K, Koval K, Lane JM, McKiernan F, McKinney R, Ng A, Nieves J, O'Keefe R, Papapoulos S, Sen HT, van der Meulen MC, Weinstein RS, Whyte M, American Society for Bone and Mineral Research (2010) Atypical subtrochanteric and diaphyseal femoral fractures: report of a task force of the American Society for Bone and Mineral Research. J Bone Miner Res 25:2267-2294

9. Morgenstern H (1982) Uses of ecologic analysis in epidemiologic research. Am J Public Health 72:1336-1344

10. http://www.imi-protect.eu/documents/DUinventory_2011_6_ WORD97-2003.pdf.

11. Lunde PKM, Baksaas I, Halse M, Strommes B, Aeydvin K (1979) The methodology of drug utilization studies. In: Bergman U, Grimsson A, Wahba AHW, Werterholm B (ed) Studies in drug utilization. WHO Regional Office for Europe, Copenhagen, pp 17-28

12. WHO Collaborating Centre for Drug Statistics Methodology (2007) Complete ATC index. http://www.whocc.no/atcddd/

13. Ministerio de Sanidad, Servicios Sociales e Igualdad (2012) Portal estadístico. http://pestadistico.msc.es/PEMSC25/ArbolNodos.aspx

14. http://www.msc.es/biblioPublic/publicaciones/recursos_propios/ infMedic/docs/vol34n3SubgrATCppiosActivos.pdf. Accesed 1 April 2012

15. http://stat.ethz.ch/R-manual/R-patched/library/stats/html/ summary.lm.html

16. http://www.nice.org.uk/. Accesed 1 April 2012

17. Chesnut CH III, Skag A, Christiansen C, Recker R, Stakkestad JA, Hoiseth A, Felsenberg D, Huss H, Gilbride J, Schimmer RC, Delmas PD, Oral Ibandronate Osteoporosis Vertebral Fracture Trial in North America and Europe (BONE) (2004) Effects of oral ibandronate administered daily or intermittently on fracture risk in postmenopausal osteoporosis. J Bone Miner Res 19:1241-1249

18. Black DM, Cummings SR, Karpf DB, Cauley JA, Thompson DE, Nevitt MC, Bauer DC, Genant HK, Haskell WL, Marcus R, Ott SM, Torner JC, Quandt SA, Reiss TF, Ensrud KE (1996) Randomised trial of effect of alendronate on risk of fracture in women with existing vertebral fractures. Lancet 348:1535-1541

19. Black DM, Delmas PD, Eastell R, Reid IR, Boonen S, Cauley JA, Cosman F, Lakatos P, Leung PC, Man Z, Mautalen C, Mesenbrink P, Hu H, Caminis J, Tong K, Rosario-Jansen T, Krasnow J, Hue TF, Sellmeyer D, Eriksen EF, Cummings SR, for the HORIZON Pivotal Fracture Trial (2007) Once-yearly zoledronic acid for treatment of osteoporosis. N Engl J Med 356:1809-1822

20. McClung MR, Geusens P, Miller PD, Zippel H, Bensen WG, Roux C, Adami S, Fogelman I, Diamond T, Eastell R, Meunier PJ, Reginster JY, for the Hip Intervention Program (HIP) Study Group (2001) Effect of risedronate on the risk of hip fracture in elderly women. N Engl J Med 344:333-340

21. Wells GA, Cranney A, Peterson J, Boucher M, Shea B, Robinson V, Coyle D, Tugwell P (2008) Alendronate for the primary and 
secondary prevention of osteoporotic fractures in postmenopausal women. Cochrane Database Syst Rev (1):CD001155

22. Feldstein AC, Weycker D, Nichols GA, Oster G, Rosales G, Boardman DL, Perrin N (2009) Effectiveness of bisphosphonate therapy in a community setting. Bone 44:153-159

23. Erviti J, Timoner J, Alonso A, Gorricho J, López A, Huerta C, Oliva B, Gil M, De Abajo F (2011) Oral bisphosphonates and hip fracture risk in elderly women. Pharmacoepidemiol Drug Saf 20:S28

24. Park-Wyllie LY, Mamdani MM, Juurlink DN, Hawker GA, Gunraj N, Austin PC, Whelan DB, Weiler PJ, Laupacis A (2011) Bisphosphonate use and the risk of subtrochanteric or femoral shaft fractures in older women. JAMA 305:783-789

25. Schilcher J, Michaëlsson K, Aspenberg P (2011) Bisphosphonate use and atypical fractures of the femoral shaft. N Engl J Med 364:17281737

26. Sellmeyer DE (2010) Atypical fractures as a potential complication of long-term bisphosphonate therapy. JAMA 304:480-484

27. Wang Z, Bhattacharyya T (2011) Trends in incidence of subtrochanteric fragility fractures and bisphosphonate use among the US elderly, 1996-2007. J Bone Miner Res 26:553-560
28. Fisher A, Martin J, Srikusalanukul W, Davis M (2010) Bisphosphonate use and hip fracture epidemiology: ecologic proof from the contrary. Clin Interv Aging 5:355-62

29. Hernández JL, Olmos JM, Alonso MA, González-Fernández CR, Martínez J, Pajarón M, Llorca J, González-Macías J (2006) Trend in hip fracture epidemiology over a 14-year period in a Spanish population. Osteoporos Int 17:464-470

30. Guilley E, Chevalley T, Herrmann F, Baccino D, Hoffmeyer P, Rapin CH, Rizzoli R (2008) Reversal of the hip fracture secular trend is related to a decrease in the incidence in institutiondwelling elderly women. Osteoporos Int 19:1741-1747

31. Brauer CA, Coca-Perraillon M, Cutler DM, Rosen AB (2009) Incidence and mortality of hip fractures in the United States. JAMA 302:1573-1579

32. Abrahamsen B, Vestergaard P (2010) Declining incidence of hip fractures and the extent of use of anti-osteoporotic therapy in Denmark 1997-2006. Osteoporos Int 21:373-830

33. Barba R, Losa JE, Guijarro C, Zapatero A (2006) Reliability of minimal basic data set in the diagnosis of thromboembolic disease. Med Clin 127:255-257 